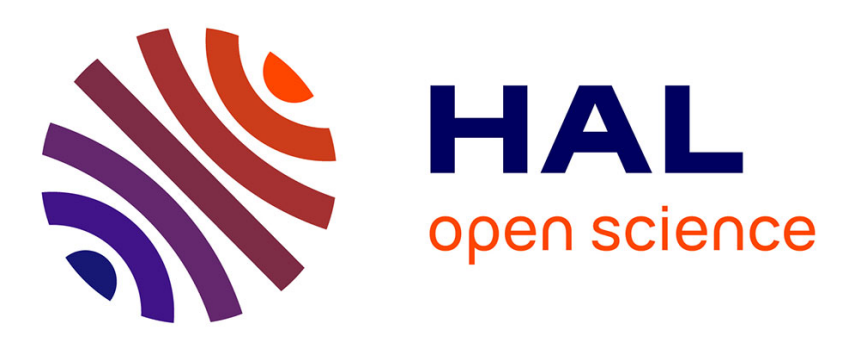

\title{
Energy Dissipation in Very High Cycle Fatigue for Polycrystalline Pure Copper and Armco Iron
}

Antoine Blanche, Chong Wang, Ngoc Lam Phung, Nicolas Ranc, Véronique

Favier, Danièle Wagner, Claude Bathias, André Chrysochoos

\section{To cite this version:}

Antoine Blanche, Chong Wang, Ngoc Lam Phung, Nicolas Ranc, Véronique Favier, et al.. Energy Dissipation in Very High Cycle Fatigue for Polycrystalline Pure Copper and Armco Iron. Key Engineering Materials, 2016, 664, pp.33-46. 10.4028/www.scientific.net/KEM.664.33 . hal-01687141

\section{HAL Id: hal-01687141 \\ https://hal.parisnanterre.fr/hal-01687141}

Submitted on 18 Jan 2018

HAL is a multi-disciplinary open access archive for the deposit and dissemination of scientific research documents, whether they are published or not. The documents may come from teaching and research institutions in France or abroad, or from public or private research centers.
L'archive ouverte pluridisciplinaire HAL, est destinée au dépôt et à la diffusion de documents scientifiques de niveau recherche, publiés ou non, émanant des établissements d'enseignement et de recherche français ou étrangers, des laboratoires publics ou privés. 


\title{
Energy Dissipation in very high cycle fatigue for polycrystalline pure copper and Armco iron
}

\author{
BLANCHE Antoine ${ }^{1, a}$, WANG Chong ${ }^{2, b}$, PHUNG Ngoc Lam ${ }^{3, c}$, \\ RANC Nicolas ${ }^{3, d}$, FAVIER Veronique ${ }^{3, e^{*}}$, WAGNER Danièle ${ }^{2, f}$, \\ BATHIAS Claude ${ }^{2, g}$, CHRYSOCHOOS André ${ }^{1, h}$ \\ ${ }^{1}$ Laboratoire de Mécanique et Génie Civil (LMGC) UMR-CNRS, 34095 Montpellier, France \\ ${ }^{2}$ Paris Ouest Nanterre University, LEME EA 4416, 92410 Ville d'Avray, France \\ ${ }^{3}$ Arts et Metiers ParisTech, CNRS PIMM, 75013 Paris, France \\ a antoine.blanche@univ-montp2.fr, ${ }^{b}$ wangchongscu@163.com, ${ }^{\mathrm{c}}$ ngoclam250@yahoo.com, \\ 'nicolas.ranc@ensam.eu, ${ }^{\mathrm{e}}$ veronique.favier@ensam.eu, ${ }^{\mathrm{f}}$ daniele.wagner@u-paris10.fr, \\ 'claude.bathias@u-paris10.fr, ${ }^{\mathrm{h}}$ andre.chrysochoos@univ-montp2.fr
}

Keywords: Very high cycle fatigue, Persistent slip bands, Dissipation, Microstructure, Polycrystals.

\begin{abstract}
.
This paper aims at a deeper understanding of microplastic mechanisms leading to crack initiation in ductile metals in Very High Cycle Fatigue (VHCF). Fatigue tests were conducted using an ultrasonic technique at loading frequency of $20 \mathrm{kHz}$. The microplastic mechanisms are revealed via observations of slip markings at the specimen surface and self-heating measurements due to intrinsic dissipation. Pure copper and Armco iron (which contains a very low amount of carbon) were investigated. Both are single-phase ductile materials but the crystallographic structure of copper is face-centered cubic while it is body centered cubic for Armco iron. A good correlation was found between slip markings initiation and dissipation for both materials. The dissipation for both materials is of the same order of magnitude but the location, the morphology and the evolution over cycles of slip markings were found different.
\end{abstract}

\section{Introduction}

In the field of aeronautic and car industries, many structures are loaded in fatigue and must resist beyond one billion cycles, corresponding to the so-called "very high cycle fatigue regime" (VHCF or the gigacycle regime). Accelerated fatigue tests involving ultrasonic facilities with frequencies as large as few tens of kilohertz now allow studying the field of the very high cycle fatigue in a very reasonable time span. In parallel, methods based on the interpretation of the energy dissipated by cycles were developed [1]. The dissipation fields were estimated from temperature measurements using quantitative infrared techniques. Specimen self-heating is first related to microplasticity, i.e. the glide of dislocations, and progressively, to damage development. In this paper, pure copper and Armco iron (which contains a very low amount of carbon) were investigated. Both are single-phase ductile materials but the crystallographic structure of copper is face-centered cubic while it is body centered cubic for Armco iron. Both are labelled as type I materials [2] since crack initiation takes place at the surface owing to accumulation of very small but irreversible slips over very large numbers of load cycles resulting in slip markings. The term "irreversible" here refers to cyclic slip processes that cause permanent or irreversible microstructural changes in the bulk leading to damaging notch-peak geometries at the surface. This paper aims to qualitatively correlate dissipated energy and slip markings for both materials of interest during fatigue tests conducted using an ultrasonic technique at loading frequency of $20 \mathrm{kHz}$ and to compare the material responses. 


\section{Material and experimental procedure}

Experimental setup. The fatigue tests were conducted using an ultrasonic fatigue machine at 20 $\mathrm{kHz}$ with cylindrical and flat hourglass shaped specimens. The high frequency is about one thousand times higher than conventional frequencies and allows to reach the VHCF regime in a reasonable time. Moreover, high frequency loading increases the dissipated energy rate and thus generates large temperature variations that are easily detectable even by standard thermal measurement devices.

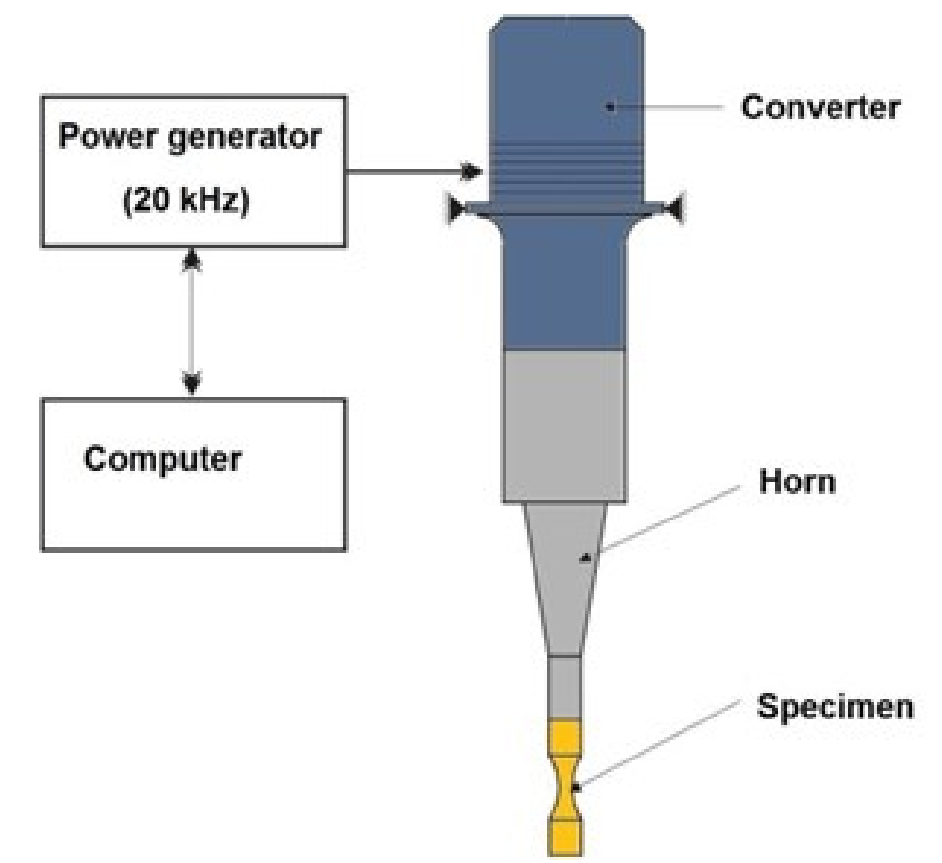

Fig. 1: Schematic representation of the piezoelectric system

The experimental setup essentially includes the three components [3-4] shown in Fig. 1:

- a piezoelectric converter, which transforms an electrical signal into a displacement

- a horn, which amplifies this displacement amplitude

- a specimen screwed on the horn and free of stress at its bottom extremity.

This dynamic loading machine and the "elastic" specimen are designed so that the free resonant frequency of the system in the first longitudinal mode is $20 \mathrm{kHz}$. This system is then calibrated with a laser extensometer to obtain the relation between the displacement amplitude on the horn edge and the input electrical signal. The strain and stress amplitudes along the specimen were estimated by a one-dimensional elastic calculation for both specimen geometries. The strain amplitude was found in a good agreement with the experimental measurement obtained by the strain gages. As an example, the geometry and the stress amplitude distribution in pure copper specimens are presented in Fig. 2 [5]. 

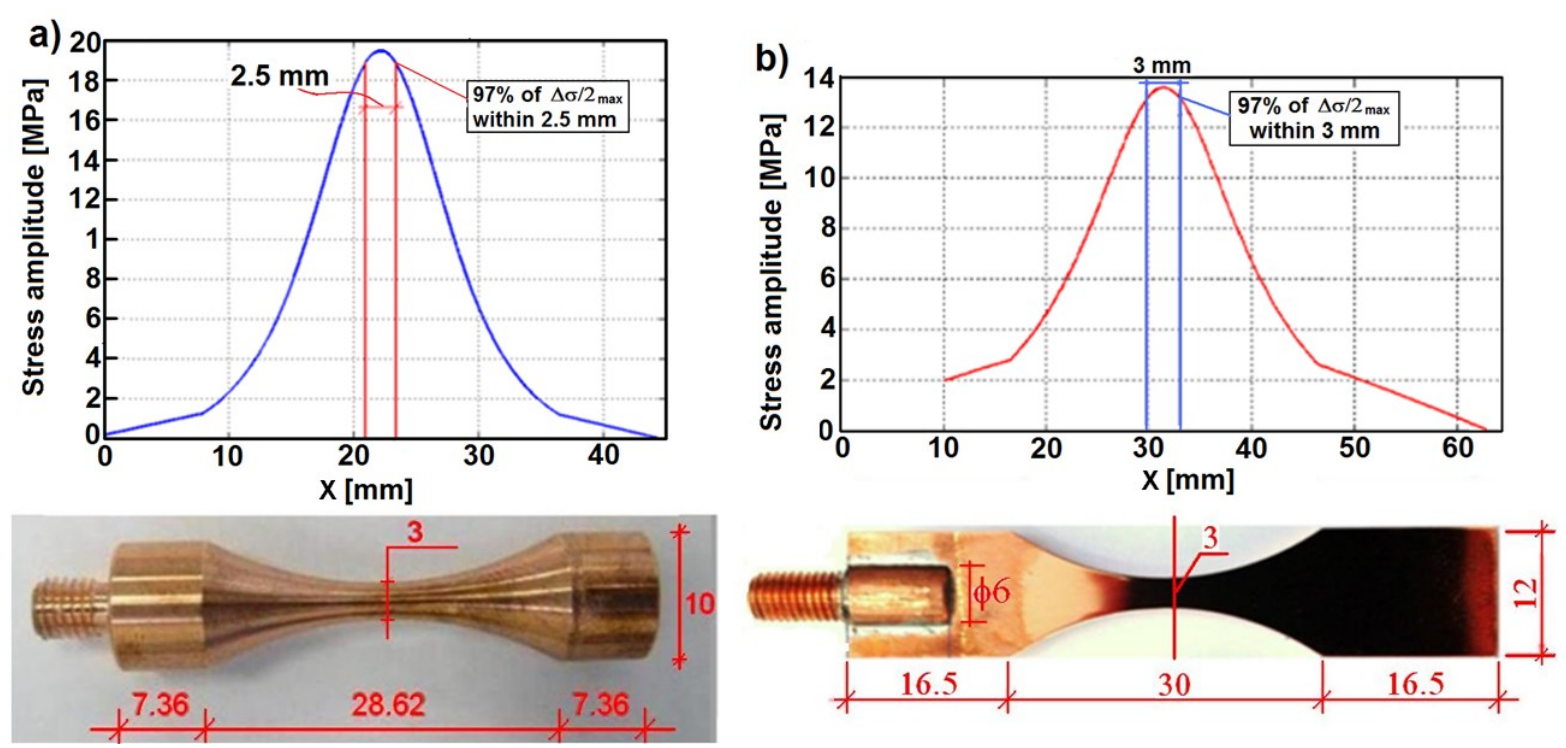

Fig. 2: Ultrasonic fatigue specimens and stress distributions along the specimen axis (a) cylindrical hourglass shaped specimen (b) flat hourglass shaped specimen [5].

Material. Commercial polycrystalline copper in initial form of a hot rolled plate of $14 \mathrm{~mm}$ of thickness was tested. The specimens were extracted from the center of the plate. The Armco iron was extracted from extruded bars or sheets. The microstructure of both materials is presented in Fig. 3. The micrographs were obtained from Electron Back Scattering Diffraction technique. The mean grain size for both materials was about $30 \mu \mathrm{m}$. The copper contained a lot of annealed twins. Copper specimens were heat treated to relieve the residual stress without change of microstructure: at $250^{\circ} \mathrm{C}$ for $60 \mathrm{~min}$. Then, a procedure of mechanical and electrolytical polishing was executed till remove all hardened layers on surface specimen [5]. As a result, before testing, the specimens were mirror polished and without residual stresses. The Young modulus in calculations was $E_{d}=130$ $\mathrm{GPa}[6]$ for pure copper and $\mathrm{E}_{\mathrm{d}}=210 \mathrm{GPa}$ for Armco iron.
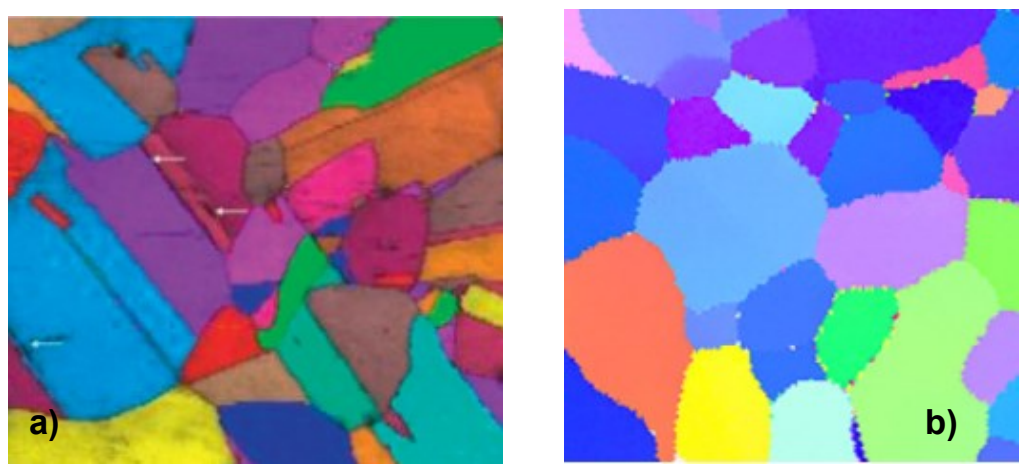

$50 \mu \mathrm{m}$

Fig. 3: Electron Back Scattering Diffraction map of polycrystals: a) pure copper [5] and b) Armco iron [7]

Experimental procedure. To perform experiments up to the VHCF regime, ultrasonic equipment at a testing frequency of $20 \mathrm{kHz}$ was used. The S-N curve of the material in the VHCF regime was first established. The fatigue tests were carried-out with cylindrical specimens for pure copper and with flat specimens for Armco iron at various stress amplitudes with a constant stress ratio $\left(\sigma_{\max } / \sigma_{\min }\right) \mathrm{R}=-1$. The fracture surfaces were observed using a scanning electron microscope. In order to prevent from a heating effect at high stress amplitudes, the specimens were cooled by a cold 
air gun during the test till rupture. To study the formation and development of slip markings on the specimen surface at very low stress amplitudes and after very high numbers of cycles, the flat specimens were used. This type of specimen is appropriate to periodically observe the microstructure while assessing temperature fields with an infrared camera to derive the corresponding intrinsic dissipation patterns. Indeed, the experiments were periodically interrupted after several specified numbers of cycles for surface observations.

\section{Calorimetric analysis}

Heat diffusion model. Although ultrasonic fatigue tests are dynamic mechanical processes, they are considered as quasi-static processes from a thermodynamic standpoint (see the statement of the local state axiom in [8]). Consequently, a finite set of variables can be chosen to describe the equilibrium material state. This generally involves the absolute temperature $T$, the (small) strain tensor $\varepsilon$ and a vector $\alpha$ of $N$ internal state variables. Combining the local expressions of the first and second principles of Thermodynamics, and assuming the Fourier heat conduction law, the local heat diffusion equation can be written as:

$\rho C \dot{T}-\operatorname{div}(k \operatorname{grad}(T))=d_{1}+s_{\text {the }}+s_{\text {thc }}+r_{\text {ext }}$

where $\rho$ is the mass density, $C=-T \psi_{T T}$ the specific heat, $\psi$ the Helmholtz free energy, $k$ an isotropic conduction tensor. The left hand side of this equation is a differential operator applied to $T$ while its right hand side gathers different heat sources. These are in turn: the intrinsic dissipation $d_{1}=\sigma: \dot{\varepsilon}-\rho \psi_{, \varepsilon}: \dot{\varepsilon}-\rho \psi_{\alpha} \cdot \dot{\alpha}$, where $\sigma$ is the Cauchy stress tensor, the thermoelastic source $s_{\text {the }}$, the other possible thermomechanical coupling sources $s_{t h c}$ ( with $\left.s_{t h e}+s_{t h c}=\rho T \psi_{T \varepsilon}: \dot{\varepsilon}+\rho T \psi_{T \alpha} \cdot \dot{\alpha}\right)$ and the external volume heat supply $r_{\text {ext }}$.

The local heat diffusion equation can be simplified assuming the following hypotheses [9-10]:

- The parameters $\rho$ and $C$ are material constants, independent of the state variables.

- The isotropic conduction tensor $k$ is also a material constant independent of the state variables.

- Thermoelastic effects induced by the thermo-dilatability are the only thermomechanical coupling factors considered hereafter (experiments on pure copper close to room temperature).

- Because of the thermal inertia, the thermal gradients slowly vary during the tests as compared to the characteristic cyclic loading time. Moreover, the mean velocity field vanishes over a cycle for such periodic loading. Consequently, the convective terms of the total time derivative of the temperature were neglected.

- The external heat supply is time independent. The equilibrium temperature field $T_{0}$ verifies $-k \Delta T_{0}=r_{e x t}$. The temperature variations are noted $\theta=T-T_{0}$.

Under these hypotheses, the local heat diffusion equation is simplified into the following form:

$$
\rho C \frac{\partial \theta}{\partial t}-k \Delta \theta=d_{1}+s_{\text {the }}
$$

A 1D calorimetric analysis has been chosen in this work assuming, in a first approximation, a uniaxial tension-compression stress state. Under the hypotheses for thin flat samples (Fig. 2), it has been shown that the mean temperature over the cross section remains close to the corresponding surface temperature given by the IR camera [10]. 
Integrating the heat equation (Eq. 2) over the sample cross section, the $1 \mathrm{D}$ diffusion equation for a non-constant cross-section can be written as [11]:

$$
\rho C\left(\frac{\partial \overline{\bar{\theta}}}{\partial t}+\frac{\overline{\bar{\theta}}}{\tau_{t h}^{1 D}}\right)-k\left(\frac{\partial^{2} \overline{\bar{\theta}}}{\partial x^{2}}+\frac{\partial \overline{\bar{\theta}}}{\partial x} \frac{S^{\prime}}{S}\right)=\overline{\bar{d}}_{1}+\overline{\bar{s}}_{t h e}
$$

where the mean temperature variation over the cross-section $\bar{\theta}(x, t)=T-T_{0}$ is identified with the surface temperature, $S^{\prime}$ being the first derivative of the cross-section $S$ while $\overline{\bar{d}}_{1}(x, t)$ and $\overline{\bar{s}}_{\text {the }}(x, t)$ are the longitudinal profiles of dissipation and thermoelastic sources. Moreover the time constant $\tau_{t h}^{1 D}$ characterizes the lateral heat exchanges by conduction, convection and radiation between the specimen and the surroundings. These exchanges are assumed to be proportional to the temperature variation (linear Fourier boundary conditions). In order to estimate the left-hand side of Eq. 3, longitudinal temperature profiles were built by averaging the surface temperature over the specimen width. Taking the loading frequency $(20 \mathrm{kHz})$ and the maximum frame rate of the IR camera (100 $\mathrm{Hz}$ ) into account, it must be stressed that the thermoelastic source amplitudes were, here, out of reach. Only the mean dissipated over one cycle were derived from the discrete, noisy thermal data.

Dissipation estimate. To compute $d_{1}$, the different partial derivative operators were estimated using spatio-temporal fitting. The local approximation functions were chosen as:

$\theta^{a p p}(x, t)=P_{1}(x) t+P_{2}(x)$

where $P_{1}(x)$ and $P_{2}(x)$ were second-order polynomials in $x$. These polynomials were identified over each approximation zone using a local least-squares method. The approximated thermal field were then used to compute the intrinsic dissipation, via an estimate of the time and space partial derivative operators of the heat equation (Eq. 3) [9].

\section{Results and discussion}

S-N curves. The S-N curves of the studied pure copper and Armco iron obtained after cooled fatigue tests are shown in Fig. 4. The S-N curve slope in VHCF is very small and about $10 \mathrm{MPa}$ per decade above $10^{7}$ cycles for both materials. In other words, the number of cycles very quickly increases with decreasing the stress amplitude. We did not observe any failure at $\Delta \sigma / 2=91.2 \mathrm{MPa}$ up to $5.4 \times 10^{9}$ cycles for pure copper and at $\Delta \sigma / 2=190 \mathrm{MPa}$ up to $6.5 \times 10^{9}$ cycles for Armco iron, at which the tests were stopped. Results obtained for pure copper are in very good agreement with Stanzl-Tschegg et al.'s experiment results obtained on similar pure polycrystalline copper [6, 12]. For both materials, no plateau that can be related to a fatigue limit was detected below $10^{10}$ cycles. 


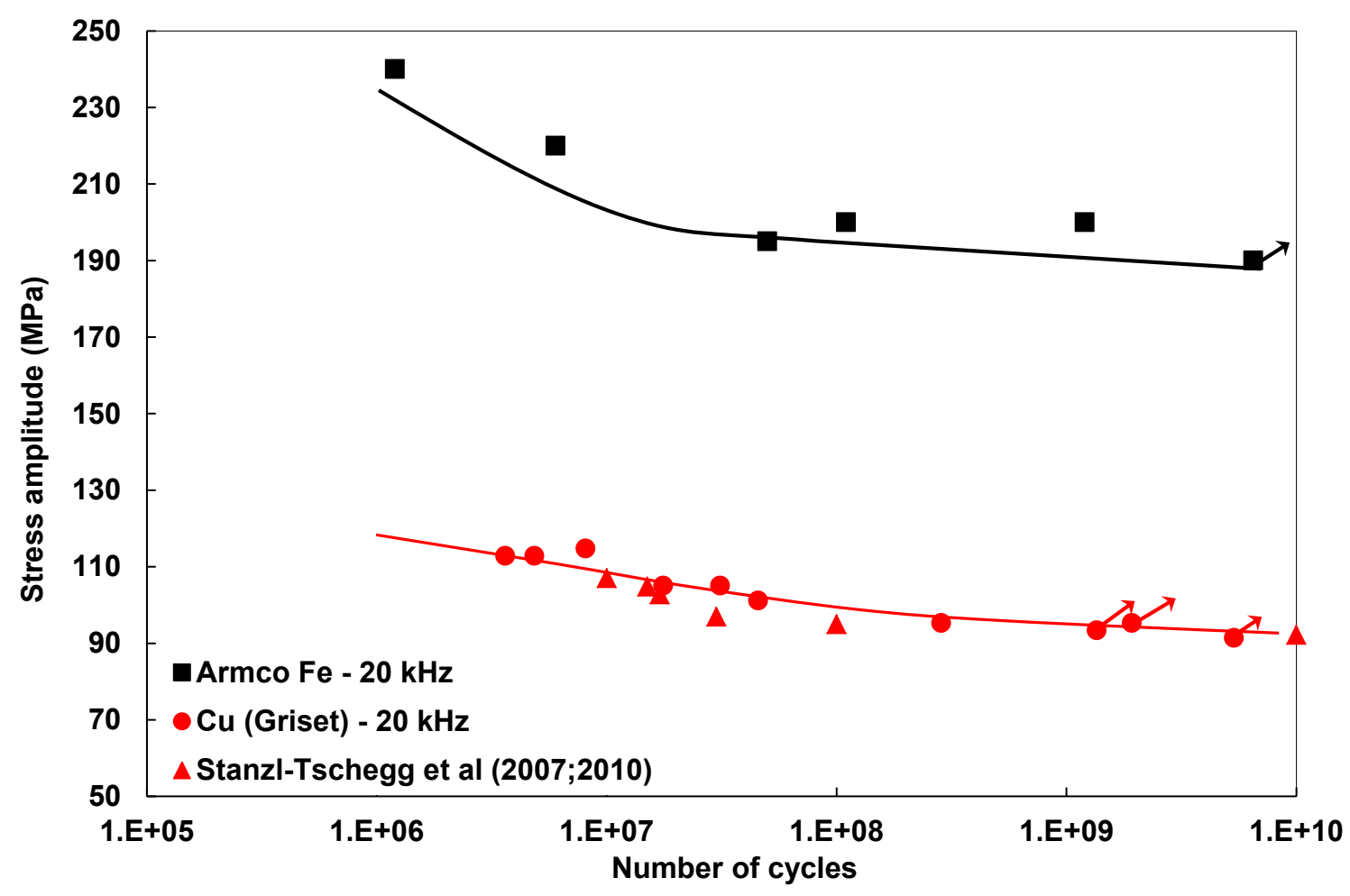

Fig. 4: S-N curves for pure copper and Armco iron obtained with an ultrasonic device and a loading frequency of $20 \mathrm{kHz}$ - Comparison with Stanzl-Tchegg et al.'s results obtained for pure copper

$$
[6,12]
$$

Fractographic observations. Fracture surface observations of the entire cross section showed that the crack initiated at the specimen surface for both materials as commonly observed for type I materials [2,13-14]. For both materials, microcracks at grain boundaries between grains with and without persistent slip markings were highlighted (Fig. 5 and Fig. 6a). Such grain boundaries were found to be the crack initiation location for pure copper specimen [5] while persistent slip bands crossing grains appeared as additional crack initiation location for Armco iron specimen (Fig. 6b) [7]. 


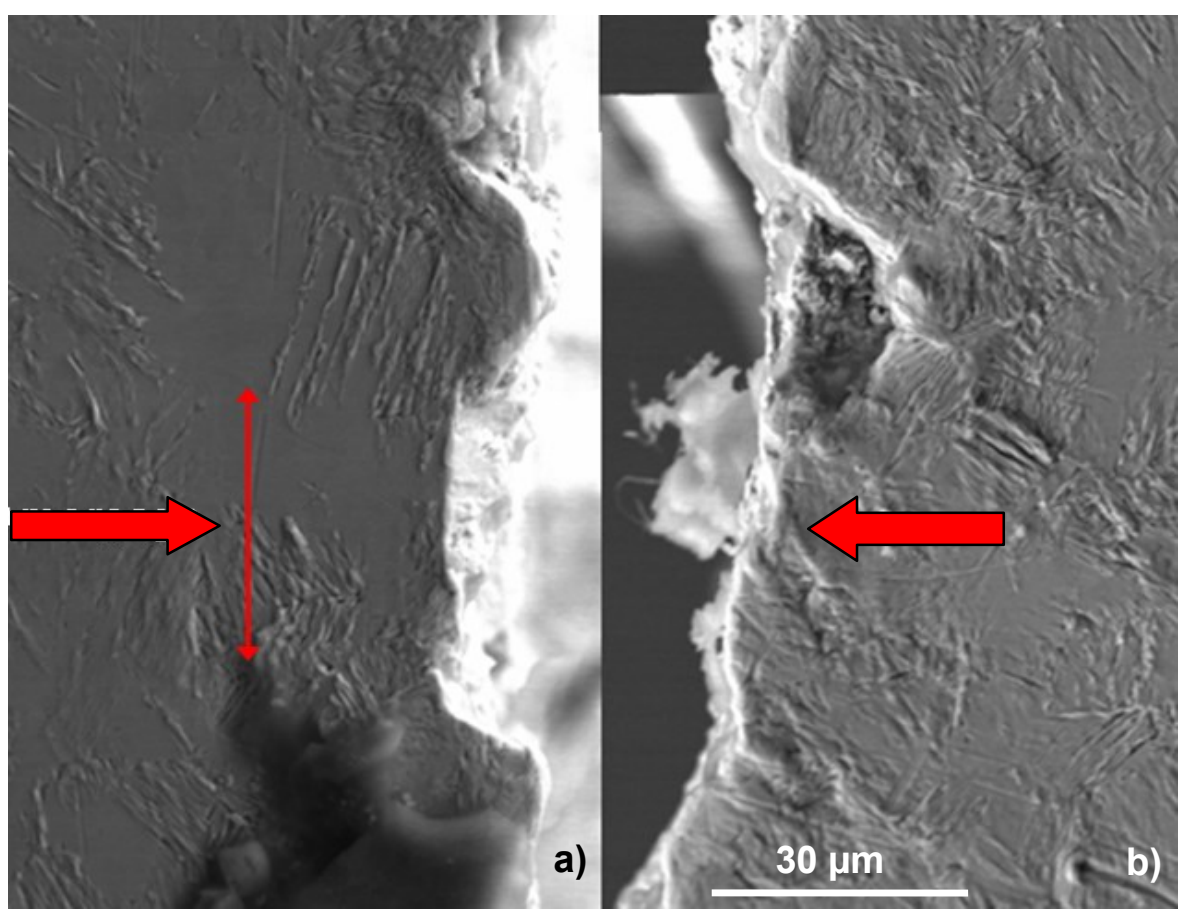

Fig. 5: Fractographic observations for a pure copper specimen loaded at stress amplitude of 105 $\mathrm{MPa} ; \mathrm{N}=3.1 \times 10^{7}$ - specimen surface normal to the fracture: a) left side, zone free of slip bands $-\mathrm{b}$ ) right side, zone marked with persistent slip bands (from [5])
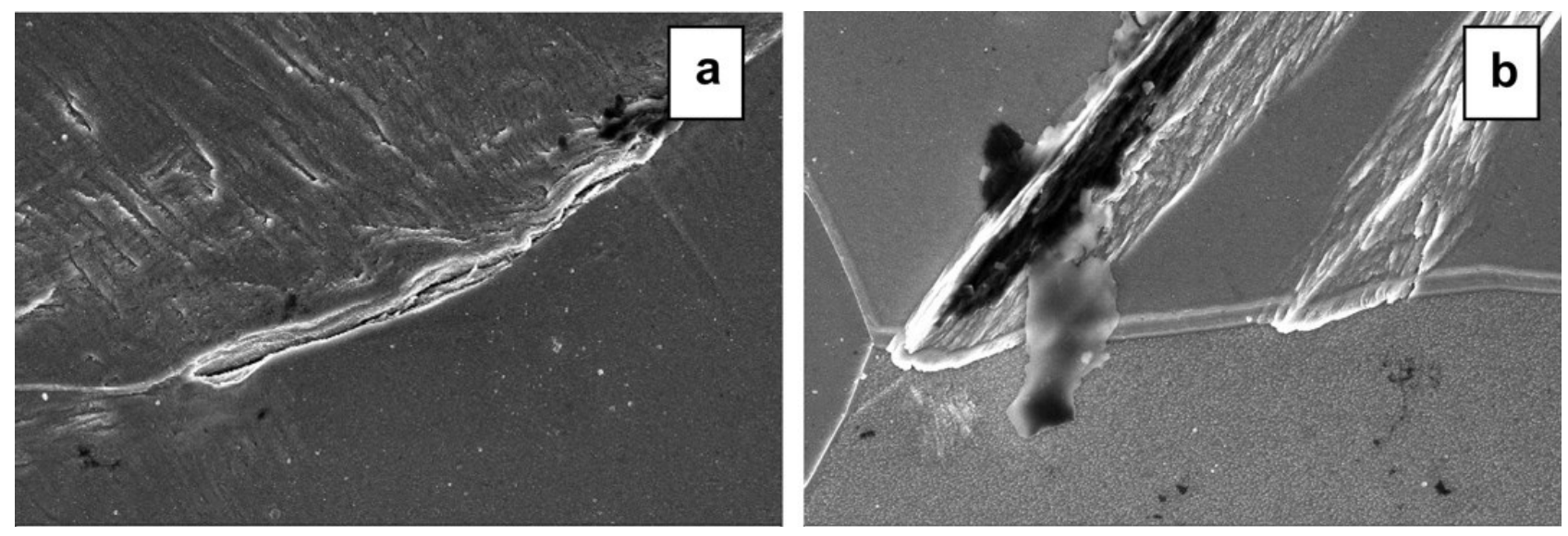

Fig. 6: Specimen surface observations for an Armco iron specimen loaded at stress amplitude of 120 $\mathrm{MPa} ; \mathrm{N}=1 \times 10^{8}-\mathrm{a}$ ) microcrack along grain boundary $\mathrm{b}$ ) microcrack in persistent slip bands (from

Self-heating and intrinsic dissipation of materials during fatigue tests. Fig. 7 exhibits the evolution of the temperature increase of copper and Armco iron specimens during fatigue tests. Higher the stress range, higher the temperature variation. The temperature has a sharp increase at the beginning of the test. No change was experimentally measured at low stress amplitudes (80 and 90 $\mathrm{MPa}$ for Armco iron) if there is no crack. On the contrary, the temperature always increases over cycles and no steady state was found for higher stress amplitudes ranging from $45.9 \mathrm{MPa}$ to 56.8 $\mathrm{MPa}$ for pure copper and from $100 \mathrm{MPa}$ to $120 \mathrm{MPa}$ for Armco iron. For both cases, these stress amplitude ranges correspond to stress amplitudes ranging from $50 \%$ to $65 \%$ of material fatigue limit estimated from cooled tests (90 MPa for pure copper and $190 \mathrm{MPa}$ for Armco iron). For both materials, fracture initiation results in a final sharp temperature increase. 

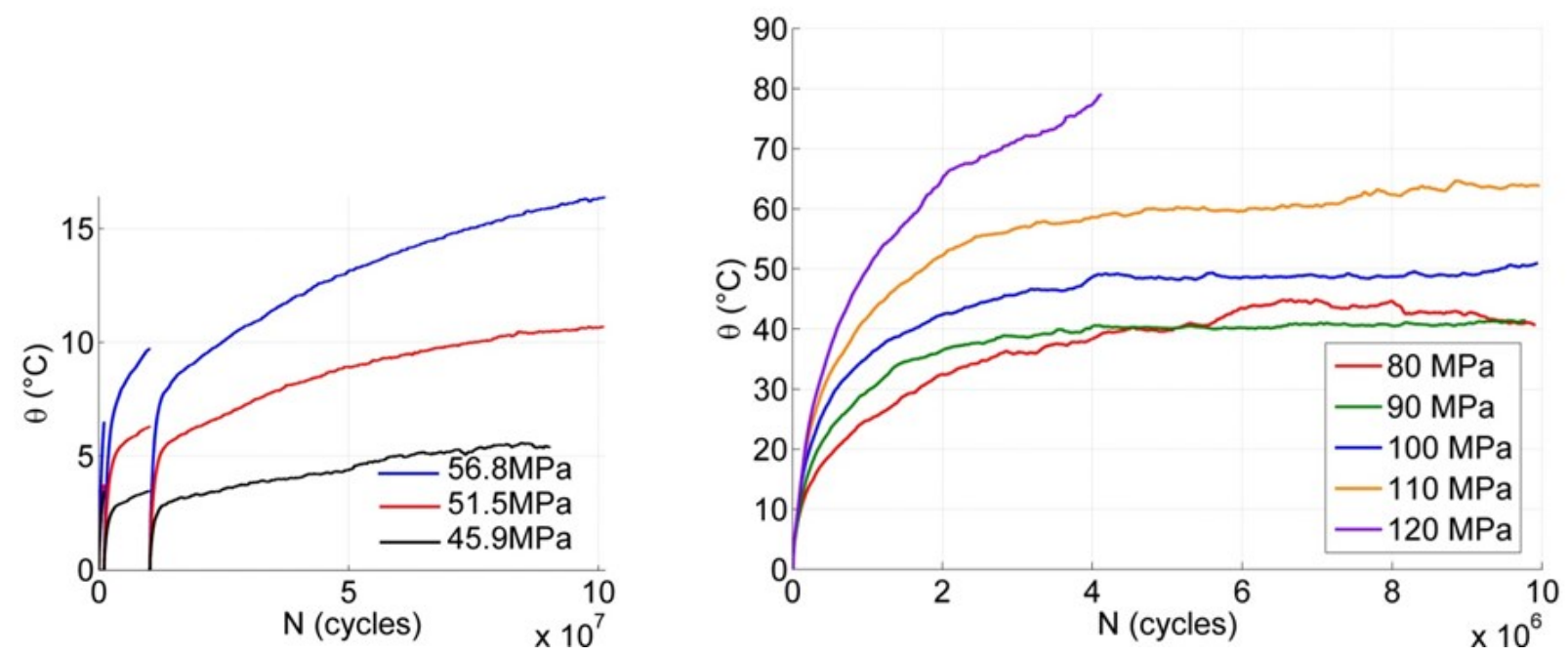

Fig. 7: Self-heating evolution over cycles and for various stress amplitudes: a) pure copper and b)

Armco iron

Fig. 8 displays the intrinsic dissipation profile along the specimen axis at the beginning, the middle and the end (rupture) of a fatigue test for Armco iron. Dissipation amounts were here divided by the heat capacity per unit volume of the material in order to get heat sources in terms of self-heating rate. Similar results were obtained for pure copper specimens. The intrinsic dissipation was higher at the specimen center as expected from the stress distribution profiles (Fig. 8). It increased over cycles especially in the zone in which the final rupture took place. It is worth noticing that the peak of dissipation moved slightly along the specimen axis over cycles. Fig. 9 corresponding to pure copper shows that the intrinsic dissipation was the highest at the place where the highest quantity of slip markings was found. However, when fracture initiated, as a lot of energy was dissipated, the peak in dissipation corresponded to the fracture initiation site. For such single phase ductile materials, crack initiation was clearly related to slip markings [5]. Locations of highest plastic activity might change over cycles but finally initiate fracture leading to a strong localization of intrinsic dissipation. 

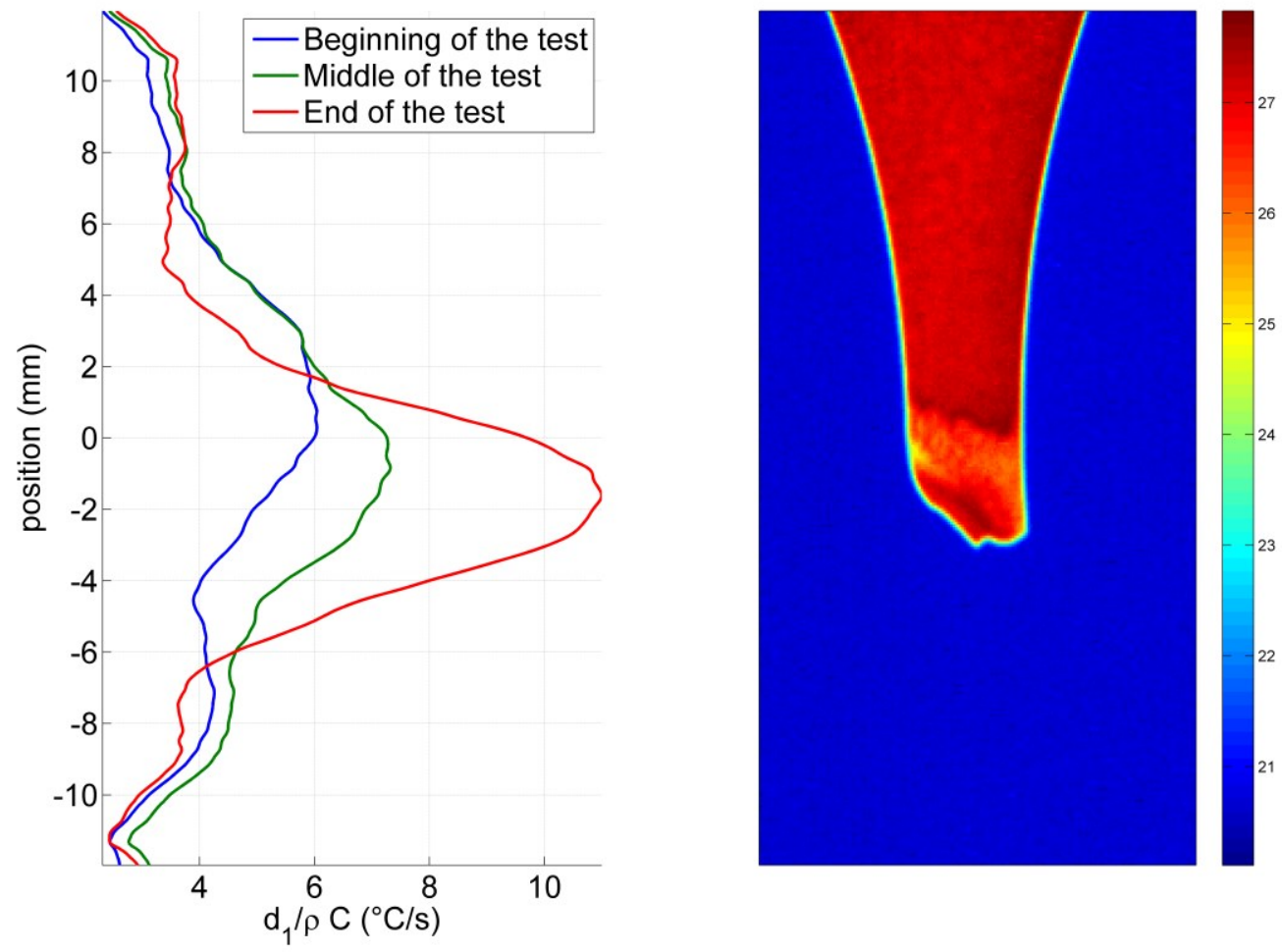

Fig. 8: Intrinsic dissipation profile along the specimen axis at the beginning, the middle and the end (rupture) of the test and corresponding infrared thermography map of the specimen at rupture for Armco iron. The temperature scale is given in ${ }^{\circ} \mathrm{C}$.

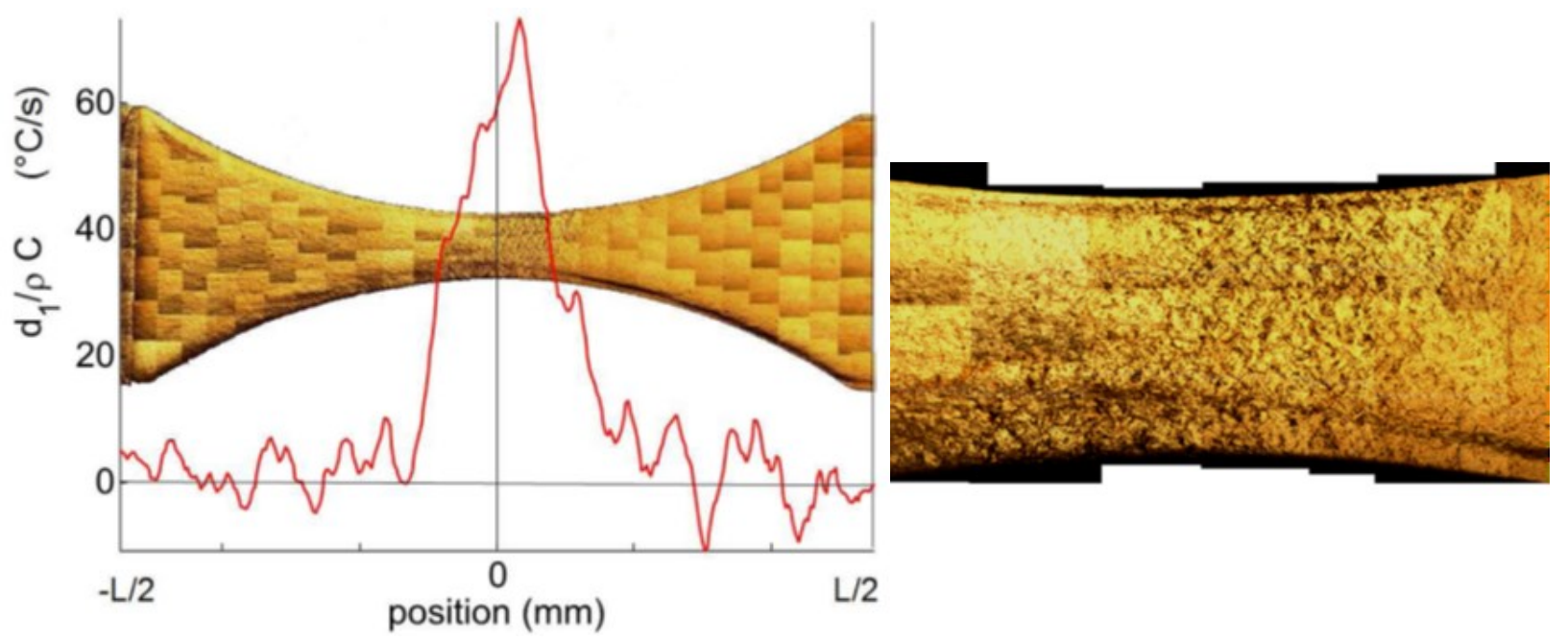

Fig. 9: a) Intrinsic dissipation profile along the specimen axis and corresponding panorama of the surface specimen obtained by optical micrographs for pure copper at $\Delta \sigma / 2=72.1 \mathrm{MPa}, 10^{7}$ cycles and $b)$ a zoom at the middle of gauge specimen

The 1D intrinsic dissipation profiles obtained at $10^{6}$ cycles were used to calculate the average dissipation over $6 \times 2 \mathrm{~mm}^{2}$ area at the specimen center. This mean dissipation is plotted as a function of the stress amplitude normalized by the fatigue limit for both materials estimated from cooled fatigue tests (Fig. 10). The mean dissipations for both materials were very close. It ranged between 1 and $5{ }^{\circ} \mathrm{C} / \mathrm{s}$ for stress amplitudes ranging from 40 and $50 \%$ of the fatigue limit. It increases with increasing stress amplitudes. 


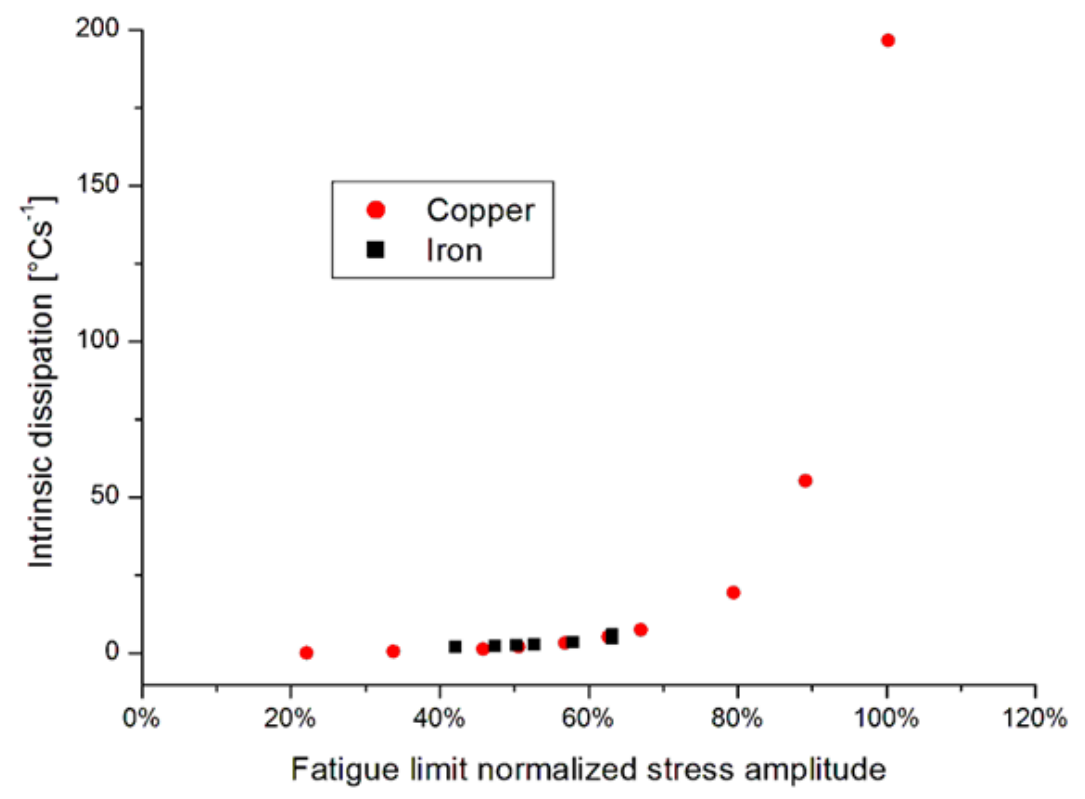

Fig. 10: Evolution of the mean intrinsic dissipation at $10^{6}$ cycles for various stress amplitudes normalized by the fatigue strength at $10^{9}$ cycles for pure copper and Armco iron

Discussion. Fig. 11 and Fig. 12 show micrographs of the surface specimens observed after fatigue loading at fatigue limit normalized stress amplitude of about $60 \%$. Slip markings were straight long and located mainly along twin boundaries for pure copper. Following Phung et al. [5], they are called slip markings of type II. Increasing the number of cycles (from $10^{8}$ to $2 \times 10^{8}$ cycles in Fig. 11) leaded to grow the slip markings [5]. In addition, some new persistent slip markings appeared 2-3 grains further. In the case of Armco iron, persistent slip markings were wavier than in the case of pure copper and cross the grain (Fig. 12). In addition, they occurred in very few grains and covered its whole surface. The neighbor grains (Fig. 12) did not exhibit any slip markings. Persistent slip markings did not progress from $10^{8}$ cycles to $2 \times 10^{9}$ cycles, except very slightly in width [7]. To sum up, pure copper and Armco iron present both persistent slip markings resulting from crystallographic slip.

However, the location of the persistent slip markings differs with regard to the polycrystalline microstructure. For pure copper, the persistent slip markings were found mainly in the vicinity of twin boundaries inclined about $45^{\circ}$ from the tensile axis while they cross the grains for Armco iron. Similar slip markings crossing grains were observed in the studied copper but for higher stress amplitudes [5]. They were labeled as slip markings of type I and are associated with the persistent slip bands (PSBs), commonly observed in the low and high cycle fatigue regimes [16]. The anisotropy coefficient value of 3.3 for copper is quite high [17]. Combining observations of slip markings and polycrystalline anisotropic elastic modelling, it was proved that it is due to: (1) higher components of the local stress tensor due to strain incompatibilities related to cubic elasticity and (2) well-oriented slip system with the slip plane parallel to the twin boundary plane [18]. Polak and Vasek [19] observed PSBs similar to type II persistent slip markings at strain amplitudes lower than the "conventional fatigue limit" $\left(\Delta \varepsilon / 2=5 \times 10^{-5}[16]\right)$ in polycrystalline copper. In the same way, Neumann and Tonnessen [20] and Peralta et al. [21] have observed PSBs along twin boundaries, about $45^{\circ}$ inclined from the loading direction but not inside the grains at low stress amplitudes. Llanes and Laird [22] showed that twin boundaries promote very early slip and PSB formation. Many studies investigating the LCF and HCF regimes for face-centered cubic metals demonstrated 
the key role of the large-angle grain and twin boundaries on crack initiation [20, 23-25]. The $>1 \mu \mathrm{m}$ high extrusion along twin boundaries could lead to crack initiation in VHCF as mentioned in Phung et al. [5]. Observing intergranular cracks on copper, Kim and Laird [26] suggested a similar possibility but for specimen loaded in the low cycle fatigue regime.

However, persistent slip markings crossing grains can also be responsible for intergranular cracks as experimentally show in the low and high cycle fatigue regimes [16, 23-24]. The crack initiation at the intersection of persistent slip bands with grain boundary is promoted by the presence of largeangle grain boundary [25]. This is clearly what happens in Armco iron. Twin does not exist in Armco iron. The anisotropy elastic coefficient is of 2.4 [27] and so lower than for copper. As a result, the slip markings appearance is more controlled by the grain orientation than neighboring effects and misorientation at grain boundaries. Therefore, the slip markings are not in the vicinity of grain boundaries but cross the grains, which are very likely the best-oriented for plasticity. Similar wavy persistent slip markings, crossing one grain, were observed by Munier [28] on $30 \mathrm{~Hz}$ cyclically loaded high-strength-low-alloy steel displaying a ferritic phase as Armco iron.

Our observations showed that intergranular cracks take place, for both materials, between one grain with surface slip markings and another grain that does not show much trace of surface deformation. Such intergranular cracks were also observed in literature [17, 29-30]. Cretegny and Saxena's findings supported the idea that the mismatch in the deformation of two neighboring grains is the driving force for the initiation of intergranular crack [30]. Besides, dislocations piles-up increases the stress concentrations at the grain boundaries. As a result, the latter are preferential sites for crack initiation. Our findings concerning Armco iron reinforce this assumption under conditions where the overall stress amplitude remains low and close to the fatigue strength in the VHCF regime. In the case of pure copper, the observation of intergranular cracks between two grains with and without slip bands sustains a crack initiation related to the intersection of persistent slip bands with grain boundary rather than the large height of slip markings of type II, along a twin boundary. Note that in the high cycle regime, cracks mainly initiate at the interface between the matrix and the PSB in polycrystals as it is in single crystals [16].

The difference in slip markings morphology probably results from the dislocation motion mechanisms which depend on the crystallographic structure (face-centered cubic for copper and body centered cubic for Armco iron). As far as the evolution of the surface during the fatigue test, slip markings did not seem to change greatly for Armco iron. On the contrary, slip markings gradually grew over cycles for pure copper. Consistently, the temperature and thus dissipation increased over cycles proving that plastic activity was growing. The reason for the different evolution of the temperature between the materials is not yet understood. 

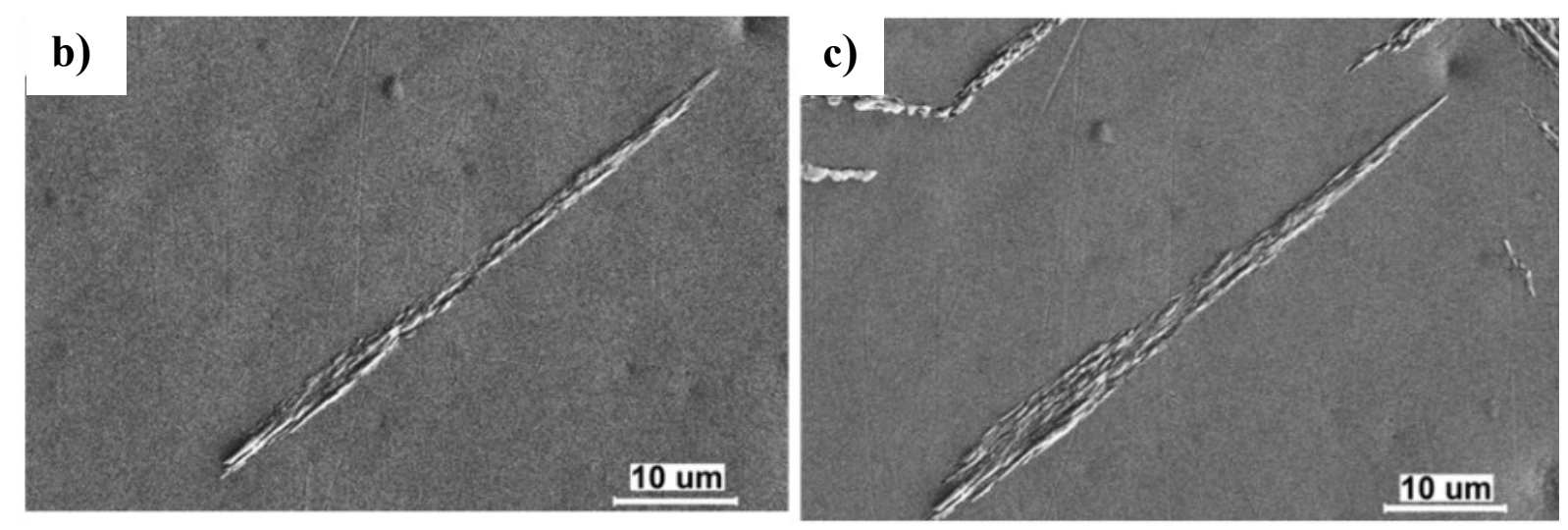

Fig. 11: Micrographs of the pure copper surface specimens observed after fatigue loading at a fatigue limit normalized stress amplitude of about 60\% (55 MPa) (scanning electronic microscope)

a) after $10^{8}$ cycles and b) after $2 \times 10^{8}$ cycles
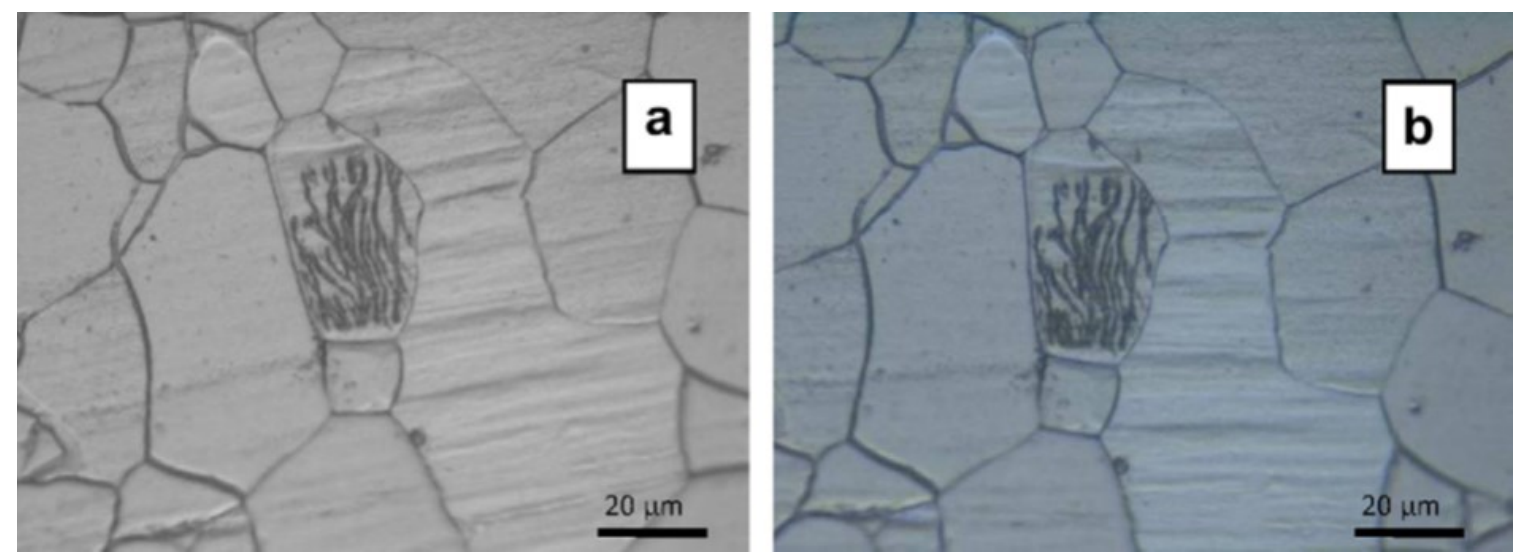

Fig. 12: Micrographs of the Armco iron surface specimens observed after $10^{8}$ cycles fatigue loading at a fatigue limit normalized stress amplitude of about $60 \%$ (optical microscope): a) $10^{8}$ cycles and b) $2 \times 10^{9}$ cycles

\section{Conclusion}

Very high cycle fatigue tests were conducted on pure copper and Armco iron using an ultrasonic technique at loading frequency of $20 \mathrm{kHz}$. The microplastic mechanisms were revealed via observations of slip markings at the specimen surface and self-heating measurements due to intrinsic dissipation. Results for both materials were compared. Similar behaviors were found:

- The S-N curve slope was about $10 \mathrm{MPa}$ per decade above $10^{7}$ cycles and no plateau was detected.

- The crack leading to final fracture initiates from the specimen surface is intergranular between one grain with slip markings and another grain without slip markings.

- In the course of cycles, the temperature gradually increased for stress amplitudes ranging from $50 \%$ to $65 \%$ of the material fatigue limit before the final rupture of the specimen.

- The level of the mean dissipation, estimated far from rupture, was very close for both materials for fatigue limit normalized stress amplitude ranging between 40 and 50\%.

- A good correlation was found between slip markings and dissipation location.

However, discrepancies also were underlined:

- The morphology and location of slip markings for fatigue limit normalized stress amplitude ranging of about $60 \%$ were different: straight and located along twin boundaries for copper, 
wavy and crossing very few grains for Armco iron. These differences were related to the anisotropic elastic coefficient and the polycrystalline microstructure of the metals.

- In the course of cycles, the slip markings grew and new slip markings appeared for pure copper while no strong change was observed for Armco iron.

\section{Acknowledgements}

We would like to acknowledge the Agence Nationale de la Recherche France ANR-09-BLAN0025-01 for the funding that enabled this work to be carried out and Professor Haël Mughrabi for our interesting scientific discussions.

\section{References}

[1] A. Blanche, A. Chrysochoos, N. Ranc, V. Favier, Dissipation Assessments During Dynamic Very High Cycle Fatigue Tests, Experimental Mechnanics (2014) 1-11.

[2] H. Mughrabi, On multi-stage fatigue life diagram and the relevant life controlling mechanisms in ultra-high cycle fatigue, 25 (2002) 755-764.

[3] C. Bathias, P. Paris, Gigacycle fatigue in mechanical practice, Dekker, M. CRC Press, 2004.

[4] C. Bathias, Piezoelectric fatigue testing machines and devices, International Journal of Fatigue, 28 (2006) 1438-1445.

[5] N. L. Phung, V. Favier, N. Ranc, F. Vales, H. Mughrabi, Very high cycle fatigue of copper: Evolution, morphology and locations of surface slip markings, International Journal of Fatigue, 63 (2014) 68-77.

[6] S. Stanzl-Tschegg, H. Mughrabi, B. Schönbauer, Life-time and cyclic slip of copper in the VHCF-regime, International Journal of Fatigue, 29 (2007) 2050-2059.

[7] C. Wang, D. Wagner, Q. Y. Wang, C. Bathias, Gigacycle fatigue initiation mechanism in Armco iron, International Journal of Fatigue, 45 (2012) 91-97.

[8] P. Germain, Q. S. Nguyen, P. Suquet, Continuum Thermomechanics, Journal of Applied Mechanics-Transactions of the Asme, 50 (1983) 1010-1020.

[9] T. Boulanger, A. Chrysochoos, C. Mabru, A. Galtier, Calorimetric analysis of dissipative and thermoelastic effects associated with the fatigue behavior of steels, International Journal of Fatigue, 26 (2004) 221-229.

[10] B. Berthel, A. Chrysochoos, B. Wattrisse, A. Galtier, Infrared Image Processing for the Calorimetric Analysis of Fatigue Phenomena, Experimental Mechanics, 28 (2008) 79-90.

[11] C. Doudard, S. Calloch, F. Hild, S. Roux, Identification of heat source fields from infra-red thermography: determination of 'self-heating' in a dual-phase steel by using a dog bone sample 42 (2010) 55-62.

[12] S. E. Stanzl-Tschegg, B. Schönbauer, Mechanisms of strain localization, crack initiation and fracture of polycrystalline copper in the VHCF regime, International Journal of Fatigue, 32 (2010) 886-893.

[13] H. W. Höppel, L. May, M. Prell, M. Göken, Influence of grain size and precipitation state on the fatigue lives and deformation mechanisms of CP aluminium and AA6082 in the VHCFregime., International Journal of Fatigue, 33 (2011) 10-18.

[14] J. V. Cartensen, H. Mayer, Very high cycle fatigue of thin walled tubes made from austenitic stainless steel, Fatigue of Engineering materials and structures, 25 (2002) 837-844.

[15] C. Wang, A. Blanche, D. Wagner, A. Chrysochoos, C. Bathias, Dissipative and microstructural effects associated with fatigue crack initiation on an Armco iron, International Journal of Fatigue, 58 (2014) 152-157. 
[16] H. Mughrabi, Z. Wang, Deformation of polycrystals: Mechanism and microstructures, in Proceesings of second Riso Inte.r Sympos. on Metall. Mater. Sci., 1981.

[17] S. Iida, K. Ohno, H. Kamimae, H. Kumagai, Tables of physical constants, 1992, p. 24.

[18] N. L. Phung, V. Favier, N. Ranc, Evaluating Schmid criterion for predicting preferential locations of persistent slip markings obtained after very high cycle fatigue for polycrystalline pure copper, International Journal of Fatigue (2015), in press.

[19] J. Polak, A. Vasek, Fatigue damage in polycrystalline copper below the fatigue limit, Butterworth-Heinemann publisher, 1994.

[20] P. Neumann, A. Tönnessen, Crack initiation at grain boundaries in FCC materials - Strength of metals and alloys, vol. 1, Oxford: Pergamon Press, 1988, p. 748.

[21] P. Peralta, C. Laird, T. E. Mitchell, Fatigue fracture at copper bicrystal interfaces: fractography, Materials Science and Engineering A, 264 (1999) 215-231.

[22] L. Llanes, C. Laird, Materials and Engineering Sciences A, 157 (1992) 21-27.

[23] N. Thompson, N. Wadsworth, N. Louat, The origin of fatigue fracture in copper, Philosophical Magazine, 1 (1956) 113-126.

[24] A. Pineau, S. Antolovitch, Fatigue intergranulaire, in Joints de grain et plasticité cristalline, sous la direction de Louisette Priester. Collection Traité, vol. Chapter 5, Directed by Louisette Priester, Traité Mécanique et Ingénierie des Matériaux. Hermès-Lavoisier: Série Matériaux, pp. 255-288, 2011.

[25] P. Zhang, S. Qu, Q. Duan, S. Wu, S. Li, Z. Wang, Low-cycle fatigue cracking mechanisms in fcc crystalline materials, Philosophical Magazine, 91 (2010) 229-249.

[26] Y. H. Kim, C. Laird, Crack nucleation and stage I propagation in high strain fatigue - II. Mechanism, Acta Metallurgica, 26 (1978) 777-787.

[27] H. M. Ledbette, R. P. Reed, Elastic properrties of metals and alloys: iron, nickel, iron-nickel alloys, Journal of Physics and Chemistry, 2 (1973) 531-617.

[28] R. Munier, Etude de la fatigue des aciers laminés à partir de l'auto-échauffement sous sollicitation cyclique: essais, observations, modélisation et influence de la pré-déformation plastique, Université de Bretagne, Brest, 2012.

[29] J. W. Provan, Z. H. Zhai, Fatigue crack initiation and stage I propagation in polycrystalline materials I: Micromechanisms, International Journal of fatigue, 13 (1991) 99-109.

[30] L. Cretegny, A. Saxena, AFM characterization of the evolution of surface deformation during fatigue in polycrystalline copper, Acta Materialia, 49 (2001) 3755-3765. 